\title{
DOIS POEMAS LÍRICOS DE PÚBLIO PAPÍNIO EstÁCIO (SILV. 4.5; 4.7)
}

\section{TWO LYRIC POEMS BY PUBLIUS PAPINIUS STATIUS (SILV. 4.5; 4.7)}

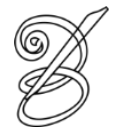 \\ Traduzido por: \\ Leandro Dorval CARDOSO ${ }^{\mathrm{i} *}$ \\ Universidade Federal do Paraná \\ Curitiba, Paraná, Brasil
}

Resumo: Neste artigo, são apresentadas as traduções dos dois únicos poemas escritos em versos líricos das Silvas (Siluae), reunião de cinco livros de poesias de ocasião escritas pelo autor latino Públio Papínio Estácio (50 - 95/6 d.C.). Compostos em estrofes alcaicas (4.5) e sáficas menores (4.7), os poemas foram traduzidos para o português com uma proposta poética que inclui o uso de diferentes versos da tradição métrica em vernáculo, com vistas a recriar as combinações latinas.

Palavras-chave: Públio Papínio Estácio. Silvas. Poesia lírica latina. Tradução. Literatura latina.

Abstract: In this paper, translations of the only two poems written in lyric meters in Silvae, a collection of five occasional poetry books written by the Roman author Publius Papinius Statius (AD 50 - 95/6), are presented. Composed in alcaic meter (4.5) and Sapphic stanzas (4.7), the poems were translated into Portuguese with a poetic proposal that includes the use of different meters from the vernacular tradition, to recreate Latin combinations. Keywords: Publius Papinius Statius. Silvae. Roman lyric poetry. Translation. Latin literature.

RECEBIDO EM: 5 de setembro de 2019

ACEITO EM: 25 de novembro de 2019

PUBLICADO EM: março 2020 


\section{Autor e obra}

$\mathrm{P}$ úblio Papínio Estácio (Nápoles, 50? - 95/96) foi um dos maiores nomes da poesia romana do Período Flaviano. Autor de uma épica em doze cantos sobre a batalha dos sete generais contra Tebas, a Tebaida, e de outra, que nos restou inacabada por causa de sua morte, sobre Aquiles, a Aquileida, Estácio também se dedicou à comumente chamada poesia de ocasião. Durante sua vida, mais especificamente entre os anos de 91/92 e 95/96, o napolitano publicou quatro livros de poemas de assuntos e metros variados, somando vinte e oito poemas, aos quais, possivelmente após sua morte, foi unido um quinto livro, com outros cinco poemas. Sob o título de Siluae, as "Silvas" (ou "Selvas"), o volume traz poemas escritos desde o ano 89 até a morte do autor ${ }^{\text {ii }}$. Com matéria poética diversificada, cantando desde a estátua do imperador Domiciano (Silv. 1.1) até a morte de seu puer delicatus (Silv. 5.5), Estácio fez jus ao título atribuído ao conjunto de seus poemas: no latim, silua pode-se referir a uma floresta ou, dentre outras possibilidades, a um conjunto de diferentes assuntos. Some-se a essa diversidade, a variação métrica dos poemas, pouca, é certo, mas presente: embora predominem hexâmetros datílicos, há hendecassilábicos e estrofes líricas (alcaicas e sáficas menores).

Ora são justamente os poemas em estrofes líricas que se apresentam em tradução poética. O poema 4.5 das Silvas canta Septímio Severo, um conterrâneo e muito provável antepassado do imperador romano Lúcio Septímio Severo (193-211 d.C.). Nascido em Léptis Magna, na Líbia, Severo é dito itálico por Estácio (v. 45-46), que busca enaltecê-lo defendendo que nenhuma pessoa, por causa de suas qualidades, ousaria dizer que Severo não cresceu na Urbe. Escrito em estrofes alcaicas no original, verso bastante apreciado por Horácio em suas Odes,o poema destaca-se do restante da obra por ser o único nesse padrão métrico, que a tradução buscou manter com uma estrofe em português composta por dois hendecassílabos com acentos obrigatórios na $5^{\mathrm{a}}, 8^{\mathrm{a}}$ e $11^{\mathrm{a}}$ sílabas, seguidos por um eneassílabo com acentos obrigatórios na $5^{\mathrm{a}}$ e $9^{\mathrm{a}}$ sílabas, e um decassílabo heroico ou sáfico. Em 4.7, por sua vez, Estácio celebra o nascimento do filho de Víbio Máximo, por cuja dignidade e eloquência o poeta declara ter respeito no prefácio do mesmo livro quarto das Silvas (praef. 16-18) ${ }^{\mathrm{iii}}$, e deseja o seu rápido retorno para Roma. Também peculiar por sua métrica, "Para Víbio Máximo" foi escrito em estrofes sáficas menores, que a tradução recriou com três hendecassílabos de acentos em sílabas ímpares (obrigatórios na $7^{\mathrm{a}}$ e $11^{\mathrm{a}}$ sílabas) e um pentassílabo também com acentos em sílabas ímpares (obrigatórios apenas na $5^{\mathrm{a}}$ sílaba). 


\section{Para Septímio Severo (Estácio, Silv. 4.5)}

De exígua lavoura contente com as honras,

onde os Teucros lares venera a prisca Alba,

Severo, o facundo e valoroso,

não com as frequentes cordas eu saúdo.

Feroz, às Arcturas Parrásias o inverno

já seguiu, premido por sóis elevados,

as terras e o mar já reluzindo,

diminuído a um zéfiro o Aquilão.

Ora, com ânuas folhas vernais, um a um

descalvam-se galhos, são novos das aves

os prantos e o canto desusado,

que firmaram no inerte sol hiberno.

A nós, pouca terra e uma vígil fogueira

e um teto por lume frequente manchado

consolam - e, obtido da quartilha

onde inda agora fermentou, Lieu.

Nem os mil rebanhos lanígeros balem,

nem vacas aos doces adúlteros mugem;

somente, se acaso então cantar,

o mudo campo a seu senhor responde.

Primeira, porém, pra mim, depois da pátria,

na estima, essa terra; os meus carmes aqui

a virgem, das guerras a rainha,

com o ouro de César estimou amável. 
assim que o agradável certame do amigo,

com esforço, de todo seu peito alentaste,

tal Cástor tremia-se ante a todo estrépito das Bébrices areias.

Gerou-te, nas longínquas Sirtes impérvia, pois, Léptis, que logo vai messes trazer

das Índias e a exótica, aos Sabeus perfumados, canela lhes tomar?

Que, então um bebê, gatinhou nas colinas de Roma Septímio, quem não pensará?

Que à fonte Juturna, abandonados os seios, se nutriu, quem vai negar?

$142 \quad$ Não pasma a coragem: de súbito em porto Ausônio, dos vaus sem saber Africanos, entras e, adotado, nas Etruscas corredeiras, menino ainda, nadas.

Pequeno, depois, entre as proles da cúria, contente com o lume da púrpura estreita cresces, mas labores desmedidos persegues com patrícia inclinação.

Sermão não Fenício, nem roupas em ti, nem senso estrangeiros: Itálico, Itálico!

$\mathrm{Na}$ Urbe e em Romanos batalhões há, que a Líbia enobreçam, procedentes.

Jovial, mesmo o Fórum ruidoso, é a voz, mas nada corrupta essa tua eloquência; a espada em silêncio na bainha, 
exceto se empunhar ordena um sócio.

Mas o agro no peito é mais certo, e a quietude, quer seja nas sedes do pai, quer nos plainos

Veientes, quer sobre os frondejantes

Hérnicos cimos, quer na velha Cures.

Aqui, seus assuntos com termos e livres

medidas permites; por vezes, contudo,

lembrando de nós, sob respeitoso

antro, redobra tu o esconso bárbito.

\section{Para Víbio Máximo (Estácio, Silv. 4.7)}

Tu, que longe em largo campo já andaste,

ora, ó brava Erato, heroicas empreitadas

distancia, e a obra imensa pra menores

círculos restringe;

tu também, que és rei das líricas coortes,

por um tempo dá-me jus de novo plectro,

se por certo eu consagrei em Lácio canto,

Píndaro, tua Tebas.

Para Máximo, abrandar eu tento o carme;

que de um mirto intonso, agora, se recolha

a guirlanda; e, aguda a sede agora, eu beba de mais puro rio.

Quando, a ti, ao doce Lácio mandarão os Dalmácios montes, donde, visto Dite, volta o pálido mineiro, do arrancado ouro igual na cor? 
Eis a mim, nascido em terra mais vizinha, inda não retêm com o porto seu, ameno, calmas angras, nem a trompa conhecida entre as tropas de Héctor.

Às Camenas nossas há sem ti marasmo, e depois do que costuma vem o próprio rei de Timbra, e à meta já primeira hesita, eis, o meu Aquiles.

Sendo tu fiel mentor, por certo, a nossa, torturada com árdua lima, pois, Tebaida com lealdade audaz intenta da Mantuana fama as alegrias.

144 Mas à mora damos vênia, pois com fausta prole os teus penates vácuos tu fundaste. Ó tão festo dia! Eis chega-nos, porquanto, um segundo Máximo!

À escassez de filho, fuja-se com empenho, à que aguça hostil herdeiro com clamores, suplicando (ah, pejo!) a próximo supremo companheiro a morte!

A escassez de filho enterre-se sem choro: na ocupada casa resta o ansioso incólume, pretendendo espólios fúnebres e a própria pira computando.

Que por muito tempo o nobre infante dure, que por um caminho a muitos não possível cresça nos costumes pátrios, e com os feitos 
desafie o avô.

Tu, ao jovem, vais teus gládios mencionar,

os que, então, no Eoo a Orontes impuseste,

das insígnias de encilhadas tropas mestre,

com propício Cástor.

Aqueloutro como, atrás do fúlmen célere

do invencível César, cáustica, aos fugentes

Sármatas, a regra impôs, de sob o mesmo

céu viver pra sempre.

Mas tuas artes o menino aprenda à frente,

pelas quais, trilhado o mundo dos antigos,

obras de Salústio, o breve, e as da Timávia

prole converteste.

\section{REFERÊNCIAS}

CARDOSO, Leandro D. A Tebaida, de Públio Papínio Estácio: introdução, tradução e comentários (cantos I-V). 2018. 3v. (360, 360, 403 f.). Tese (Doutor em Estudos Literários) FCL, UNESP, Araraquara-SP, 2018.

STATIUS, Publius P. Siluae. Ed. Aldus Marastoni. Leipzig: B. G. B. Teubner Verlagsgesellschaft, 1970.

WHITE, Peter. Vibius Maximus, the friend of Statius. Historia: Zeitschrift für Alte Geschichte, v. 22, n. 2, p. 295-301, 1973.

\footnotetext{
i* Leandro Dorval CARDOSO - Bacharel em Letras com ênfase em Estudas da Tradução (2009) pela Universidade Federal do Paraná. Mestre em Letras (2012) pela mesma instituição. Doutor em Estudos Literários (2018) pela Universidade Estadual Paulista Júlio de Mesquita Filho. Professor substituto de Língua e Literatura Latina da Universidade Federal do Paraná, Departamento de Polonês, Alemão e Letras Clássicas. Curitiba, Paraná, Brasil. Currículo acadêmico: http://lattes.cnpq.br/3965158419565470

ORCID: https://orcid.org/0000-0003-4683-3449

E-mail: leandrodorvalc@gmail.com

ii Para uma discussão mais detalhada sobre as datas de nascimento e morte de Estácio, bem como sobre as de suas publicações, cf. Cardoso (2018, p. 19-22) e as referências aí indicadas.

iii Marcial (11.106) e Plínio, o Jovem (Ep. 3.2) também se referem a um Víbio Máximo; o homenageado por Estácio é costumeiramente identificado com o Víbio Máximo que se tornou prefeito do Egito no início do séc. II. Sobre a identidade do personagem, cf. White (1973) e as referências aí indicadas.
} 